\begin{tabular}{|c|c|c|}
\hline 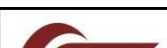 & Racic 6 (1) (2021) & naticien \\
\hline$M$ & JURNAL RAB CONTRUCTION RESEARCH & A. \\
\hline $\begin{array}{l}\text { UNIVERSITAS } \\
\text { ABDURRAB }\end{array}$ & http://jurnal.univrab.ac.id/index.php/racic & 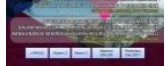 \\
\hline
\end{tabular}

\title{
STRATEGI PENANGANAN LALU LINTAS PADA KAWASAN CENTRAL BUSINESS DISTRICT (CBD) DI KOTA PEKANBARU BERDASARKAN PENDEKATAN TEKNIS
}

\author{
Agru Maulana ${ }^{1}$, Ari Sandhyavitri ${ }^{2}$, Muhammad Ikhsan ${ }^{3}$ \\ ${ }^{1}$ Mahasiswa Magister Teknik Sipil, Universitas Riau \\ ${ }^{2}$ Dosen Magister Teknik Sipil, Universitas Riau \\ ${ }^{3}$ Dosen Magister Teknik Sipil, Universitas Riau \\ Jl Hr Soebrantas Km 12,5 Pekanbaru \\ E-mail: agrumaulana@gmail.com \\ Info Artikel
}

Sejarah Artikel:

Diterima : 19 Desember 2020

Disetujui : 29 Juni 2021

Dipublikasikan : 30 Juni 2021

Keywords:

Vissim, Tingkat Pelayanan Jalan, Central Business District

\begin{abstract}
Abstrak
Masalah kemacetan di Indonesia seringkali diselesaikan hanya dengan memperbaiki jaringan jalan melalui pelebaran atau penambahan jalan. Ini adalah strategi praktis untuk menanggapi permintaan akan peningkatan transportasi, tetapi strategi ini bersifat temporal dan sebenarnya mendorong tingkat pertumbuhan kendaraan bermotor yang lebih tinggi di kota. Manajemen lalu lintas merupakan salah satu strategi manajemen lalu lintas yang memanfaatkan secara maksimal prasarana dan sarana transportasi yang ada. Kawasan Pusat Bisnis (CBD) atau Kawasan Pusat Kota (DPK) merupakan pusat dari segala aktivitas kota dan lokasi yang strategis untuk aktivitas perdagangan skala kota. Salah satu kendala lalu lintas di Kota Pekanbaru, khususnya kawasan pusat aktivitas Jalan Jenderal Sudirman (depan STC - Jalan Ir Juanda) adalah buruknya tingkat kinerja jalan baik dari segi kecepatan, volume lalu lintas maupun kepadatan kendaraan. Dari permasalahan tersebut, pemecahan masalah dilakukan melalui manajemen lalu lintas dengan menerapkan beberapa skenario menggunakan vissim yaitu penertiban pedagang kaki lima, pengendalian parkir pada jalan, sistem pengalihan satu arah dan pengaturan siklus simpang bersinyal. Skenario yang paling optimal adalah pengendalian tempat parkir dan perubahan sudut parkir Jalan Jenderal Sudirman dan Jalan Juanda menjadi sudut $30^{\circ}$ dan penerapan Jalan M. Yamin menjadi jalan satu arah ke Jalan Sudirman serta pengaturan siklus simpang bersinyal sehingga kinerja jalan lebih baik yaitu pada tingkat $\mathrm{C}(0,45-0,74)$.
\end{abstract}

Kata kunci: Vissim, Tingkat pelayanan Jalan, Central Business District

\begin{abstract}
The problem of congestion in Indonesia is often resolved only by improving / supplying the road network through widening or adding roads. This is a practical strategy to respond to the demand for increased transportation, but this strategy is temporal in nature and actually encourages higher growth rates of motorized vehicles in cities. Traffic management is one of the traffic management strategies that make maximum use of existing transportation infrastructure and facilities. The Central Business District (CBD) or the City Center Region $(D P K)$ is the center of all city activities and a strategic location for city-scale trading activities. One of the traffic problems in Pekanbaru City, especially the activity center area of Jalan Jenderal Sudirman (in front of STC - Jalan Ir Juanda) is the poor performance level of the road both in terms of speed, traffic volume and also the density that occurs on the Jalan Jenderal Sudirman section. . From these problems, the problem solving is through traffic management by applying several scenarios using vissim, namely controlling street vendors, on street parking control, one-way / flow diversion systems and signalized intersection cycle arrangements. The most optimal scenario is to control the parking lot and change the parking angle of Jalan General Sudirman and Jalan Juanda to an angle of 300 and the application of Jalan M. Yamin into a one-way system to Jalan Sudirman and setting the cycle of signalized intersections so that the performance of the road is smaller at the level C (0.45-0.74).
\end{abstract}

Keywords : Vissim, Level of service, Central Business District 


\section{PENDAHULUAN}

Central Business District (CBD) atau Daerah Pusat Kota (DPK) merupakan pusat segala aktivitas kota dan lokasi yang strategis untuk kegiatan perdagangan skala kota. CBD atau DPK merupakan zona dengan derajat aksesibilitas yang tinggi dalam suatu kota (Yu et al., 2015). Terdapat pasar dan banyaknya pertokoan serta perkantoran yang dapat menyebabkan terbebannya jalan-jalan di sepanjang kawasan CBD. Akibat dari itu munculnya permasalahan berupa kemacetan lalu lintas dan tingginya hambatan samping berupa pedagang kaki lima dan penggunaan badan jalan sebagai tempat parkir. Salah satu permasalahan lalu lintas di Kota Pekanbaru khususnya daerah pusat kegiatan jalan Jenderal Sudirman (depan STC - Jalan Ir Juanda) adalah buruknya tingkat kinerja ruas jalan baik dalam kecepatan ruasnya, volume lalu lintas yang melintasi dan juga kepadatan yang terjadi di ruas Jalan Jenderal Sudirman tersebut. Hasil dari pemeringkatan salah satu ruas jalan arteri yang terburuk yaitu jalan Jenderal Sudirman dengan volume sebesar 7717 smp/jam dan tingkat pelayanan D dimana artinya kriteria arus tidak stabil, kecepatan rendah dan volume mendekati kapasitas jalan. (Laporan Umum Kota Pekanbaru Tahun 2018;PKJI 2014). Agar permasalahan lalu lintas di kota Pekanbaru khususnya daerah pusat kegiatan Jalan Sudirman tidak semakin parah, dan juga permasalahan lalu lintas tersebut membutuhkan penanganan maka dalam rangka meningkatkan kinerja jaringan jalan yang akan melancarkan pergerakan lalu lintas perlu dilakukan penelitian.

\section{TINJAUAN PUSTAKA}

\section{Strategi Penanganan Lalu Lintas}

Strategi merupakan perencanaan dan manajemen untuk mencapai tujuan. Strategi sebagai pola keputusan dalam perencanaan untuk mencapai tujuan dan sasaran yang disusun. (salusu, 2006). Menurut Undangundang 22 tahun 2009, lalu lintas adalah gerak kendaraan dan orang di ruang lalu lintas jalan. Strategi penanganan lalu lintas merupakan rumusan perencanaan komprehensif tentang bagaimana menangani permasalahan lalu lintas di daerah pusat kota atau Central Business District. (Olayiwola et al., 2014)

\section{Strategi Manajemen Lalu Lintas}

Tabel 1. Strategi dan Teknik Manajemen Lalu Lintas

\begin{tabular}{c|l}
\hline \multicolumn{1}{c|}{ Strategi } & \multicolumn{1}{c}{ Teknik } \\
\hline \multirow{4}{*}{ Manajemen Kapasitas } & 1. Perbaikan persimpangan \\
& 2. Manajemen ruas jalan : \\
& $\begin{array}{l}\text { a. Pemisahan tipe kendaraan } \\
\text { b. Kontrol "on-street parking" (tempat, waktu) } \\
\text { c. Pelebaran jalan }\end{array}$ \\
& 3. Area traffic control : \\
& a. Batasan tempat membelok \\
& b. Sistem jalan satu arah \\
& c. Koordinasi lampu lalu lintas \\
\hline \multirow{4}{*}{ Manajemen Prioritas } & 2. Prioritas bus, misal jalur khusus bus \\
& 3. Daerah pejalan kaki \\
& 4. Rute sepeda
\end{tabular}




\begin{tabular}{c|ll}
\hline & 5. & Control daerah parkir \\
\hline \multirow{3}{*}{$\begin{array}{cll}\text { Manajemen Permintaan } \\
\text { (demand) }\end{array}$} & 2. & Kebijaksanaan parkir \\
& 3. & Area and cordon licensing \\
& 4. & Batasan fisik \\
\hline
\end{tabular}

\section{Pengukuran Kinerja Lalu Lintas}

Menurut Tamin (2008), menyatakan bahwa kinerja lalu lintas perkotaan dapat dinilai dengan menggunakan parameter lalulintas yaitu untuk ruas jalan, dapat berupa V/C Rasio, kecepatan dan kepadatan lalu lintas. Sedangkan untuk persimpangan dapat berupa waktu tundaan dan panjang antrian. Jika tersedia, maka data kecelakaan lalu lintas juga dapat dipertimbangkan dalam mengevaluasi efektifitas sistem lalu lintas perkotaan.

1. Kinerja Ruas Jalan

2. Kinerja Persimpangan

3. Panjang Antrian dan Tundaan

Tabel 2. Tingkat Pelayanan Ruas Jalan

\begin{tabular}{|c|c|c|c|}
\hline $\begin{array}{c}\text { Tingkat } \\
\text { Pelayanan }\end{array}$ & & Karakteristik-Karakteristik & $\begin{array}{c}\text { Nilai v/c } \\
\text { ratio }\end{array}$ \\
\hline $\mathbf{A}$ & $\begin{array}{l}1 \\
2 \\
3\end{array}$ & $\begin{array}{l}\text { Arus Bebas dengan volume lalu lintas rendah } \\
\text { Kecepatan Perjalanan Rata-Rata } \geq 80 \mathrm{~km} / \mathrm{jam} \\
\text { Kepadatan lalu lintas rendah }\end{array}$ & $\begin{array}{c}0,00- \\
0,20\end{array}$ \\
\hline $\mathbf{B}$ & $\begin{array}{l}1 \\
2 \\
3\end{array}$ & $\begin{array}{l}\text { Arus Stabil dengan volume lalu lintas sedang } \\
\text { Kecepatan Perjalanan Rata-Rata Turun s/d } \geq 70 \mathrm{~km} / \mathrm{jam} \\
\text { Kepadatan lalu lintas rendah }\end{array}$ & $\begin{array}{c}0,20- \\
0,44\end{array}$ \\
\hline $\mathbf{C}$ & $\begin{array}{l}1 . \\
2 . \\
3\end{array}$ & $\begin{array}{l}\text { Arus Stabil dengan volume lalu lintas lebih tinggi } \\
\text { Kecepatan Perjalanan Rata-Rata Turun s/d } \geq 60 \mathrm{~km} / \mathrm{jam} \\
\text { Kepadatan lalu lintas sedang }\end{array}$ & $\begin{array}{c}0,45- \\
0,74\end{array}$ \\
\hline D & $\begin{array}{l}1 . \\
2 . \\
3\end{array}$ & $\begin{array}{l}\text { Arus Mendekati Tidak Stabil dengan volume lalu lintas tinggi } \\
\text { Kecepatan Perjalanan Rata-Rata Turun s/d } \geq 50 \mathrm{~km} / \mathrm{jam} \\
\text { Kepadatan lalu lintas sedang }\end{array}$ & $\begin{array}{c}0,75- \\
0,84\end{array}$ \\
\hline $\mathbf{E}$ & $\begin{array}{l}2 \\
\text { a1 } \\
3\end{array}$ & $\begin{array}{l}\text { Arus Tidak Stabil dengan volume lalu lintas mendekati kapasitas } \\
\text { Kecepatan Perjalanan Rata-Rata Sekitar } 30 \mathrm{~km} / \mathrm{jam} \text { untuk jalan } \\
\text { ta dan } 10 \mathrm{~km} / \text { jam untuk jalan perkotaan } \\
\text { Kepadatan lalu lintas tinggi karena hambatan internal }\end{array}$ & $\begin{array}{c}0,85- \\
1,00\end{array}$ \\
\hline $\mathbf{F}$ & $\begin{array}{l}1 \\
2 \\
3\end{array}$ & $\begin{array}{l}\text { Arus Tertahan dan terjadi antrian } \\
\text { Kecepatan Perjalanan Rata-Rata }<30 \mathrm{~km} / \mathrm{jam} \\
\text { Kepadatan lalu lintas sangat tinggi dan volume rendah }\end{array}$ & $>1,00$ \\
\hline
\end{tabular}




\section{METODE}

Pengumpulan data dilakukan dengan metode observasi. Observasi merupakan pengamatan langsung dilapangan untuk mendapatkan data langsung dari kondisi yang ada dan data sekunder yang berasal dari instansi-instansi terkait. Peneliti telah melakukan kegiatan pengumpulan data ini bersama Tim PKL pada tahun 2018. Adapun penggunaan data tersebut dapat digunakan sebagai dasar untuk melakukan analisis data. data yang digunakan dalam penelitian ini adalah data volume lalu lintas ruas jalan, inventaris ruas jalan, kecepatan kendaraan pada ruas jalan, antrian pada simpang, tundaan pada simpang, waktu siklus simpang APILL.

\section{Analisis Data}

Analisa data menggunakan langkah yaitu analisis kinerja jaringan kondisi eksisting,kemudian menganalisis pengaturan lalu lintas dengan beberapa alternatif kebijakan menggunakan vissim.

\section{Rumus Perhitungan Kapasitas Simpang Tidak Dikendalikan}

$$
\mathrm{C}=\mathrm{C}_{0} \times \mathrm{F}_{\mathrm{WX}} \mathrm{F}_{\mathrm{MX}} \mathrm{F}_{\mathrm{CSX}} \mathrm{F}_{\mathrm{RS} X} \mathrm{~F}_{\mathrm{LT} X}
$$

Keterangan :

$\mathrm{C}_{\mathrm{o}}=$ kapasitas dasar

$\mathrm{F}_{\mathrm{w}}=$ faktor penyesuaian lebar pendekat rata-rata

$\mathrm{F}_{\mathrm{M}}^{\mathrm{w}}=$ faktor penyesuaian madian jalan utama

$\mathrm{F}_{\mathrm{CS}}=$ faktor penyesuaian ukuran kota

$\mathrm{F}_{\mathrm{RS}}=$ faktor penyesuaian hambatan samping

$\mathrm{F}_{\text {LT }}=$ faktor penyesuaian belok kiri

$\mathrm{F}_{\mathrm{RT}}=$ faktor penyesuaian belok kanan

$\mathrm{F}_{\mathrm{MI}}=$ faktor penyesuaian rasio minor

Rumus Perhitungan Kapasitas Simpang Dikendalikan Lampu Lalu Lintas (APILL)

$$
\begin{gathered}
\mathrm{C}=\mathrm{S} \text { x g/waktu siklus } \\
\mathrm{S}=\mathrm{S}_{0} \times \mathrm{F}_{\mathrm{CSX}} \mathrm{F}_{\mathrm{SFX}} \mathrm{F}_{\mathrm{GX}} \mathrm{F}_{\mathrm{PX}} \mathrm{F}_{\mathrm{RT} X}
\end{gathered}
$$

Keterangan:

$\mathrm{S}_{\mathrm{o}}=$ nilai dasar

$\mathrm{F}_{\mathrm{cs}}=$ faktor penyesuaian ukuran kota

$\mathrm{F}_{\mathrm{Sf}}=$ faktor penyesuaian hambatan samping

$\mathrm{F}_{\mathrm{G}}=$ faktor penyesuaian kelandaian

$\mathrm{F}_{\mathrm{P}}=$ faktor penyesuaian parkir

$\mathrm{F}_{\mathrm{RT}}=$ faktor penyesuaian belok kanan

$\mathrm{F}_{\mathrm{LT}}=$ faktor penyesuaian belok kiri

$\mathrm{G}=$ (waktu hijau) Waktu siklus 


\section{Aplikasi Program Komputer (Software)}

Dalam melakukan peningkatan lalu lintas dibutuhkan pemodelan suatu jaringan jalan yang benar. Menurut Krajzewicz et al. (2002), meskipun lalu lintas dapat dijelaskan oleh waktu keberangkatan dan rute dengan jangka waktu tertentu, namun lalu lintas sangat dikondisikan oleh keinginan individu untuk mobilitas yang membentuk sekitar $65 \%$ dari lalu lintas. Selain itu faktor cuaca dan infrastruktur di kawasan tertentu juga dapat mempengaruhi sistem. Kebutuhan data untuk membangun suatu model menggunakan VISSIM agar bisa digunakan yaitu data geometrik jalan, volume lalu lintas, proporsi kendaraan, rute kendaraan, dan data APILL/ prioritas simpang. Sedangkan output yang dihasilkan yaitu kinerja ruas jalan, panjang tundaan, kecepatan jaringan, total waktu perjalanan.

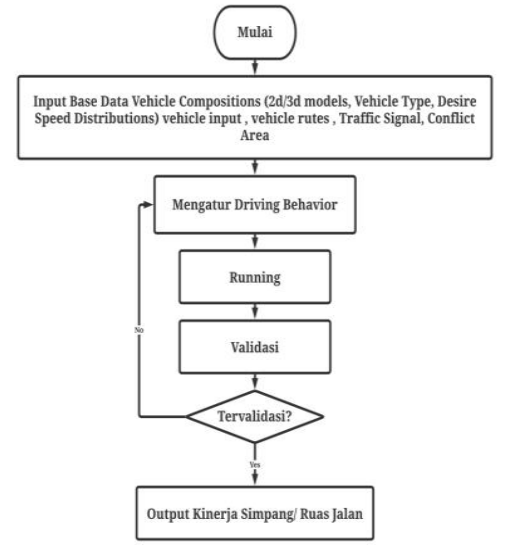

Gambar 1. Flowchart Simulasi Vissim

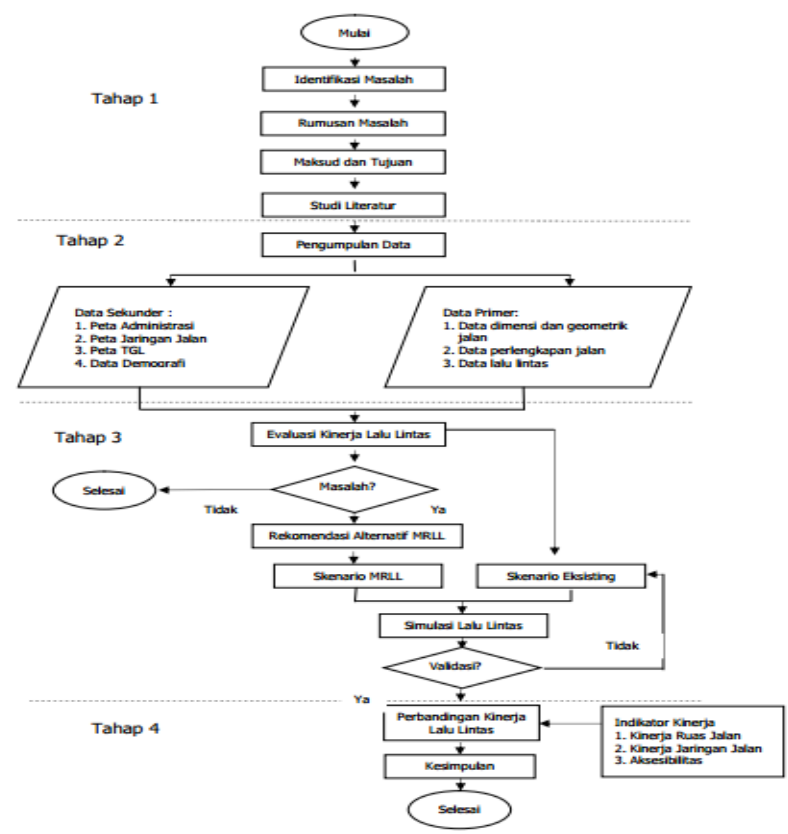

Gambar 2. Flowchart Penelitian

\section{HASIL DAN PEMBAHASAN}

\section{Kinerja Jaringan Jalan Kondisi Eksisting}


Tabel 3. Perbandingan Kinerja Ruas Jalan pada Kawasan CBD Kota Pekanbaru

\begin{tabular}{ccccccc}
\hline No & Nama Jalan & $\begin{array}{c}\text { Kapasitas } \\
\text { Jalan (C) }\end{array}$ & $\begin{array}{c}\text { Volume } \\
\text { (smp/Jam) }\end{array}$ & $\begin{array}{c}\text { V/C } \\
\text { Ratio }\end{array}$ & $\begin{array}{c}\text { Kecepatan } \\
\text { Rata-Rata } \\
\text { (km/jam) }\end{array}$ & $\begin{array}{c}\text { Level } \\
\text { of } \\
\text { Service }\end{array}$ \\
\hline 1 & Jendral Sudirman & 4851,00 & 3954 & 0,82 & 46 & $\mathrm{D}$ \\
\hline 2 & Jendral A.Yani & 3264,24 & 2634 & 0,80 & 47 & $\mathrm{D}$ \\
\hline 3 & Ir. Juanda & 3217,26 & 2390 & 0,74 & 44 & $\mathrm{C}$ \\
\hline 4 & Sam Ratulangi & 3671,25 & 2594 & 0,71 & 50 & $\mathrm{C}$ \\
\hline 5 & M. Yamin & 2396,85 & 1782 & 0,74 & 48 & $\mathrm{C}$ \\
\hline
\end{tabular}

Dari tabel 3 dapat diketahui bahwa ruas jalan yang memiliki volume lalu lintas terbesar adalah ruas Jalan Jenderal Sudirman sebesar 3954 smp/jam. Sedangkan untuk volume lalu lintas terendahnya yakni pada Jalan M. Yamin sebesar $1782 \mathrm{smp} / \mathrm{jam}$

Tabel 4. Kinerja Jaringan Jalan Eksisting

\begin{tabular}{ll}
\hline Parameter & Kinerja Jaringan Jalan \\
\hline Kecepatan Jaringan & $23 \mathrm{~km} / \mathrm{jam}$ \\
\hline Total Jarak Perjalanan & $9367 \mathrm{kendaraan} / \mathrm{km}$ \\
\hline Total Waktu Perjalanan & $391 \mathrm{kendaraan} / \mathrm{jam}$ \\
\hline Tundaan & 371,28 detik \\
\hline
\end{tabular}

Dari tabel diatas dapat diketahui bahwa kinerja jaringan jalan eksisting pada jaringan jalan kawasan tersebut, terlihat dari kecepatan jaringan jalan yaitu $23 \mathrm{~km} / \mathrm{jam}$, total jarak perjalanan yaitu 9367 kendaraan/km, total waktu perjalanan yaitu 391 kendaraan/jam dan tundaan yaitu 371,28 detik.

\section{Skema Penanganan Lalu Lintas}

Dari hasil analisis yang telah dilakukan terhadap studi yang dilakukan di kawasan CBD Kota Pekanbaru, permasalahan yang muncul dalam kawasan ini adalah terkait dengan tingkat pelayanan ruas jalan dan simpang yang mengakibatkan buruknya kinerja jaringan jalan di kawasan ini.

\section{a. Skema Penanganan Lalu Lintas Pertama}

Skema penanganan lalu lintas yang pertama dilakukan adalah dengan menata lokasi parkir yang berada di pinggir jalan pada wilayah studi, Selain itu, dilakukan pengaturan lalu lintas dengan menertibkan pedagang kaki lima dan titik lokasi penyeberangan pejalan kaki, sehingga kendaraan tidak berhenti di sembarang tempat dan tidak menghambat pergerakan arus lalu lintas di wilayah studi.

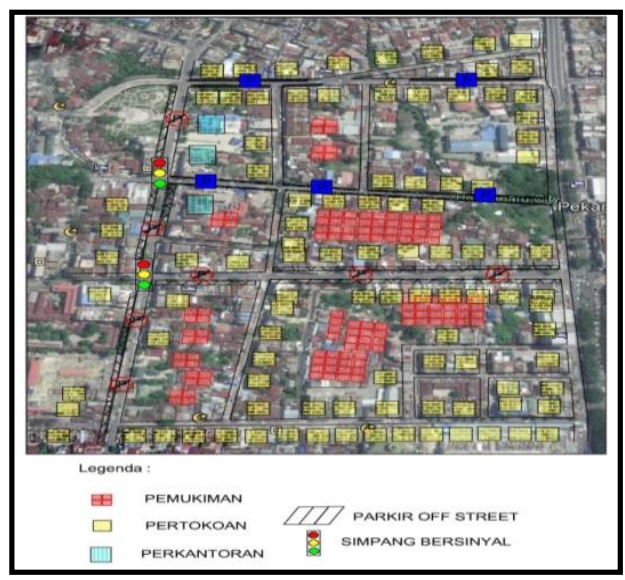


Gambar 3. Skema Penanganan Lalu Lintas Pertama

Dari hasil analisis penerapan skenario pertama kemudian di dapat kinerja ruas jalan yang dapat dilihat pada Tabel 5

Tabel 5 Kinerja Ruas Jalan pada Skenario 1

\begin{tabular}{cccccccc}
\hline \multirow{2}{*}{ No } & $\begin{array}{c}\text { Nama } \\
\text { Jalan }\end{array}$ & \multicolumn{2}{c}{ Volume (smp/jam) } & Kecepatan $(\mathbf{K m} / \mathbf{J a m})$ & \multicolumn{2}{c}{ V/C Ratio } \\
\cline { 3 - 8 } 1 & $\begin{array}{c}\text { Jendral } \\
\text { Sudirman }\end{array}$ & 3954 & 3954 & 46 & 49,73 & 0,82 & 0,78 \\
\hline 2 & $\begin{array}{c}\text { Jendral A. } \\
\text { Yani }\end{array}$ & 2634 & 2634 & 20 & 30,46 & 0,80 & 0,74 \\
\hline 3 & Ir. Juanda & 2390 & 2390 & 44 & 49,69 & 0,74 & 0,69 \\
\hline 4 & $\begin{array}{c}\text { Sam } \\
\text { Ratulangi }\end{array}$ & 2594 & 2594 & 47 & 48,79 & 0,71 & 0,66 \\
\hline 5 & M. Yamin & 1782 & 1782 & 46 & 47,86 & 0,74 & 0,74 \\
\hline
\end{tabular}

Tabel 6 Kinerja Jaringan Jalan Skenario I

\begin{tabular}{ll}
\hline Parameter & Kinerja Jaringan Jalan \\
\hline Kecepatan Jaringan & $25 \mathrm{~km} / \mathrm{jam}$ \\
\hline Total Jarak Perjalanan & $9664 \mathrm{kendaraan} / \mathrm{km}$ \\
\hline Total Waktu Perjalanan & 386,56 kendaraan $/ \mathrm{jam}$ \\
\hline Tundaan & 279,01 detik \\
\hline
\end{tabular}

Dari tabel diatas dapat diketahui bahwa setelah dilakukan skema penanganan lalu lintas yang pertama terjadi peningkatan pada jaringan jalan kawasan tersebut, terlihat dari, kecepatan jaringan jalan yang meningkat menjadi $25 \mathrm{~km} / \mathrm{jam}$, total jarak perjalanan 9664 kendaraan/km, total waktu perjalan menjadi 387 kendaraan/jam dan tundaan Menjadi 279,01 detik.

\section{b. Skema Penanganan Lalu Lintas Kedua}

Skema penanganan lalu lintas yang kedua adalah dengan membuat sirkulasi arus lalu lintas dengan sistem satu arah pada ruas jalan kolektor CBD yaitu Jalan Sam Ratulangi menuju Jalan Jendral Sudirman, sebagai penghubung menuju tempat kegiatan utama dan perubahan waktu siklus APILL pada wilayah studi yaitu pada simpang Ahmad Yani - M.Yamin dan simpang A.Yani - Samratulangi.

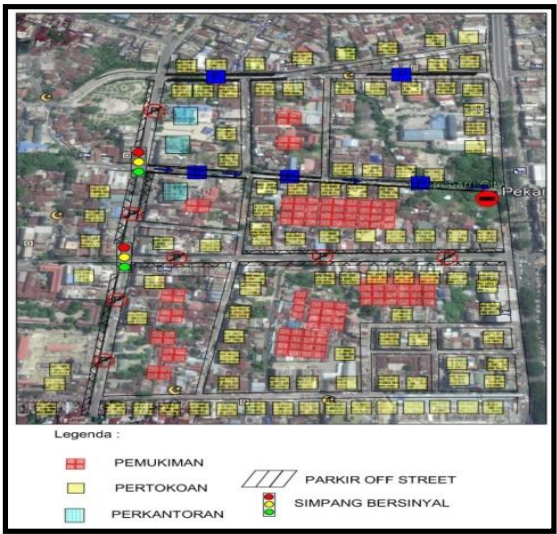

Gambar 4. Skema Penanganan Lalu Lintas Kedua 
Agru Maulana / Jurnal Rab Contruction Research 6 (1) (2021)

Tabel 7. Kinerja Ruas Jalan pada Skenario 2

\begin{tabular}{c|c|c|c|c|c|c|c}
\hline \multirow{2}{*}{ No } & \multirow{2}{*}{ Nama Jalan } & \multicolumn{2}{|c|}{ Volume (smp/jam) } & \multicolumn{2}{c|}{ Kecepatan (Km/Jam) } & \multicolumn{2}{|c}{ V/C Ratio } \\
\cline { 3 - 8 } & eksisting & skenario 2 & eksisting & skenario 2 & eksisting & skenario 2 \\
\hline 1 & $\begin{array}{c}\text { Jendral } \\
\text { Sudirman }\end{array}$ & 3954 & 3415 & 46 & 50,21 & 0,82 & 0,70 \\
\hline 2 & $\begin{array}{c}\text { Jendral A. } \\
\text { Yani }\end{array}$ & 2634 & 2402 & 20 & 30,06 & 0,80 & 0,73 \\
\hline 3 & Ir. Juanda & 2390 & 2687 & 44 & 51,12 & 0,74 & 0,74 \\
\hline 4 & $\begin{array}{c}\text { Sam } \\
\text { Ratulangi }\end{array}$ & 2594 & 2679 & 47 & 45,57 & 0,71 & 0,72 \\
\hline 5 & M. Yamin & 1782 & 1644 & 46 & 51,56 & 0,74 & 0,68 \\
\hline
\end{tabular}

Tabel 8 Kinerja Jaringan Jalan pada Skenario 2

\begin{tabular}{ll}
\hline Kinerja Jaringan Jalan & Parameter \\
\hline $26 \mathrm{~km} / \mathrm{jam}$ & Kecepatan Jaringan \\
\hline 9454 kendaraan/km & Total Jarak Perjalanan \\
\hline 363,61 kendaraan/jam & Total Waktu Perjalanan \\
\hline 183,57 detik & Tundaan \\
\hline
\end{tabular}

Dari tabel diatas dapat diketahui bahwa setelah dilakukan skenario kedua terjadi peningkatan kinerja jaringan jalan pada kawasan tersebut, terlihat dari kecepatan jaringan jalan yang meningkat menjadi 26 $\mathrm{km} / \mathrm{jam}$, total jarak perjalanan 9454 kendaraan/km, dan total waktu perjalanan menjadi 364 kendaraan/jam.

\section{c. Skema Penanganan Lalu Lintas Ketiga}

Skema penanganan lalu lintas yang ketiga adalah dengan menata lokasi parkir dan penertiban pedagang kaki lima pada ruas jalan Jendral Sudirman dan Jalan Juanda, kemudian membuat sirkulasi arus lalu lintas dengan sistem satu arah pada ruas jalan kolektor CBD yaitu Jalan M.yamin.

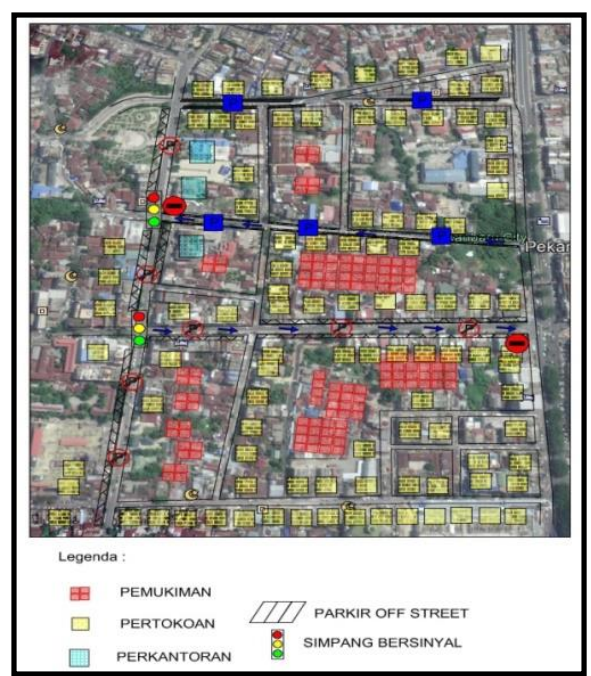

Gambar 4. Skema Penanganan Lalu Lintas Ketiga

Dari hasil analisis penerapan skenario ke tiga kemudian di dapat kinerja ruas jalan yang dapat dilihat pada Tabel 9 
Tabel 9 Kinerja Ruas Jalan pada Skenario 3

\begin{tabular}{cccccccc}
\hline \multirow{2}{*}{ No } & $\begin{array}{c}\text { Nama } \\
\text { Jalan }\end{array}$ & \multicolumn{2}{c}{ Volume (smp/jam) } & Kecepatan $(\mathbf{K m} / \mathbf{J a m})$ & \multicolumn{2}{c}{ V/C Ratio } \\
\cline { 3 - 8 } & eksisting & skenario 3 & eksisting & skenario 3 & eksisting & skenario 3 \\
\hline & $\begin{array}{c}\text { Jendral } \\
\text { Sudirman }\end{array}$ & 3954 & 3548 & 46 & 51,22 & 0,82 & 0,69 \\
\hline 2 & $\begin{array}{c}\text { Jend A. } \\
\text { Yani }\end{array}$ & 2634 & 2365 & 20 & 23,89 & 0,80 & 0,72 \\
\hline 3 & Ir. Juanda & 2390 & 2636 & 44 & 49,73 & 0,74 & 0,73 \\
\hline 4 & $\begin{array}{c}\text { Sam } \\
\text { Ratulangi }\end{array}$ & 2594 & 2624 & 47 & 51,91 & 0,71 & 0,71 \\
\hline 5 & M. Yamin & 1782 & 1662 & 46 & 52,16 & 0,74 & 0,69 \\
\hline
\end{tabular}

Tabel 10 Kinerja Jaringan Jalan pada Skenario 3

\begin{tabular}{ll}
\hline Parameter & Kinerja Jaringan Jalan \\
\hline Kecepatan Jaringan & $27 \mathrm{~km} / \mathrm{jam}$ \\
\hline Total Jarak Perjalanan & $9686 \mathrm{kendaraan} / \mathrm{km}$ \\
\hline Total Waktu Perjalanan & 358,74 kendaraan/jam \\
\hline Tundaan & 161,96 detik \\
\hline
\end{tabular}

Dari Tabel 10 dapat diketahui bahwa setelah dilakukan skenario ketiga terjadi peningkatan kinerja jaringan jalan pada kawasan tersebut, terlihat dari kecepatan jaringan jalan yang meningkat menjadi 27 $\mathrm{km} / \mathrm{jam}$, total jarak perjalanan 9686 kendaraan/km, dan total waktu perjalan menjadi 359 kendaraan/jam.

Perbandingan Kinerja Lalu Lintas

\begin{tabular}{ccccc}
\hline $\begin{array}{c}\text { Skema Lalu } \\
\text { Lintas }\end{array}$ & Tundaan & Kecepatan & $\begin{array}{c}\text { Total Jarak } \\
\text { Perjalanan }\end{array}$ & $\begin{array}{c}\text { Total Waktu } \\
\text { Perjalanan }\end{array}$ \\
\cline { 2 - 5 } (kend/km) & (kend/jam) \\
\hline $\begin{array}{c}\text { Kondisi } \\
\text { Eksisting }\end{array}$ & 371,28 & 15 & 9367 & 391 \\
\hline Skenario 1 & 279,01 & 25 & 9664 & 387 \\
\hline Skenario 2 & 183,57 & 26 & 9454 & 364 \\
\hline Skenario 3 & 161,96 & 27 & 9686 & 359 \\
\hline
\end{tabular}

\section{SIMPULAN}

Berdasarkan hasil analisis yang telah dilakukan maka dapat disimpulkan sebagai berikut:

1. Kinerja lalu lintas di Kawasan CBD Kota Pekanbaru pada tahun 2020 yang diperoleh dari hasil pembebanan lalu lintas sebagai berikut:

a. Tundaan rata-rata 371,28 detik,

b. Kecepatan jaringan $23 \mathrm{~km} / \mathrm{jam}$,

c. Total jarak perjalanan 9367 kendaraan $/ \mathrm{km}$,

d. Total waktu perjalanan 391 kendaraan/jam

2. Perekayasaan Lalu lintas pada kondisi eksiting menggunakan tiga skenario. Skenario 1 yaitu Menertibkan Parkir kendaraan dan kegiatan Pedagang kaki lima agar mengurangi hambatan samping di luar jalan wilayah studi. Skenario 2 yaitu penambahan waktu siklus di wilayah studi dan mengubah sirkulasi sistem satu arah untuk ruas jalan samratulangi menuju arah sudirman. Skenario 3 yaitu 
dengan menata lokasi parkir dan penertiban pedagang kaki pada ruas jalan Jend.Sudirman dan Jalan Ahmad Yani, membuat sirkulasi arus lalu lintas dengan sistem satu arah pada ruas jalan kolektor CBD yaitu Jalan M.yamin sebagai penghubung dan jalan arteri CBD sebagai tempat kegiatan utama.

3. Berikut merupakan kinerja lalu lintas sesudah dilakukannya perekayasaan lalu lintas dengan tiga skema penanganan lalu lintas yang diusulkan.

Skenario 1:

a. Tundaan rata-rata 279,01 detik,

b. Kecepatan jaringan $25 \mathrm{~km} / \mathrm{jam}$,

c. Total jarak perjalanan 9664 kendaraan/km,

d. Total waktu perjalanan 387 kendaraan/jam

Skenario 2:

a. Tundaan rata-rata 183,57 detik,

b. Kecepatan jaringan $26 \mathrm{~km} / \mathrm{jam}$,

c. Total jarak perjalanan 9454 kendaraan/km,

d. Total waktu perjalanan 364 kendaraan/jam

Skenario 3:

a. Tundaan rata-rata 161,96 detik,

b. Kecepatan jaringan $27 \mathrm{~km} / \mathrm{jam}$,

c. Total jarak perjalanan 9454 kendaraan $/ \mathrm{km}$,

d. Total waktu perjalanan 359 kendaraan/jam

Skenario terbaik yaitu skenario 3 yang dipilih berdasarkan penilaian parameter kinerja jaringan dan kebutuhan dari kondisi eksisting kawasan CBD Kota Pekanbaru. Dari perbandingan tersebut dapat diketahui bahwa antara tundaan dengan kecepatan memiliki keterkaitan yang berbanding terbalik dimana kecepatan tinggi maka tundaan akan rendah begitupun sebaliknya. Total jarak perjalanan dan total waktu perjalanan terjadi perbedaan pada setiap skenario hal ini disebabkan oleh perbedaan jarak rute atau pemilihan rute yang dipilih.

\section{DAFTAR PUSTAKA}

Dewi, H. I., Mustofa, C., \& Riyanto, T. (2016). Konsep Mixed-Use Building dan Central Business District untuk Keberlanjutan Kota. Seminar Nasional Sains Dan Teknologi, 5(November), 110.

Direktorat Jenderal Bina Marga, 1997, Manual Kapasitas Jalan Indonesia (MKJI), Departemen Pekerjaan Umum, Jakarta.

Direktorat Jenderal Bina Marga, 2004, Pedoman Pencacahan Lalu Lintas dengan Cara Manual, Departemen Pekerjaan Umum, Jakarta.

Direktorat Jenderal Bina Marga, 2004, Survei Inventarisasi Geometri Jalan Perkotaan, Departemen Pekerjaan Umum, Jakarta.

Hermawan, B. A. (2016). Manajemen dan Rekayasa Lalu Lintas Kawasan CBD Kota Bekasi. Jurnal 
Pembangunan Wilayah \& Kota, 12(1), 27. https://doi.org/10.14710/pwk.v12i1.11454

Heddy R. Agah, 2007, kondisi arus lalu-lintas, kondisi geometrik jalan dan komposisi arus lalu-lintas. Jakarta.

Keputusan Menteri No. 14, 2006, Tentang Manajemen dan Rekayasa Lalu Lintas di Jalan. Jakarta. Laporan Umum Kota Pekanbaru. (2018). Pola Umum Transportasi Darat Kota Pekanbaru.

Olayiwola, K. O., Olaseni, A. M., \& Fashina, O. (2014). Traffic Congestion Problems in Central Business District (CBD) Ikeja, Lagos Metropolis, Nigeria. Research on Humanities and Social Sciences, 4(1), 23-32.

Tamin, O.Z., 2000. Perencanaan dan Permodelan Transportasi, Bandung.

Tamin, O.Z., 2008. Perencanaan, Permodelan, dan Rekayasa Transportasi, Bandung.

Tianzi, C., Shaochen, J., \& Hongxu, Y. (2013). Comparative Study of VISSIM and SIDRA on Signalized Intersection. Procedia - Social and Behavioral Sciences, 96 (Cictp), 2004-2010.

Peraturan Menteri Perhubungan No. 96., 2015, Tentang Pedoman Pelaksanaan Kegiatan Manajemen dan Rekayasa Lalu Lintas. Jakarta.

Peraturan Pemerintah no. 32, 2011. Tentang Manajemen dan Rekayasa, Analisa Dampak, serta Manajemen Kebutuhan Lalu Lintas, Jakarta.

Undang-undang Lalu Lintas no. 22., 2009. Tentang Rekayasa Lalu Lintas, Jakarta

Yu, W., Ai, T., \& Shao, S. (2015). The analysis and delimitation of Central Business District using network kernel density estimation. Journal of Transport Geography, 45, 32-47. https://doi.org/10.1016/j.jtrangeo.2015.04.008 